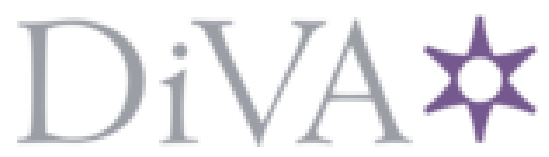

http://www.diva-portal.org

This is the published version of a paper presented at IEEE IECON 2014,Dallas, TX - USA October 29 November 1, 2014.

Citation for the original published paper:

Almas, M., Vanfretti, L. (2014)

Implementation of Conventional and Phasor Based Power System Stabilizing Controls for Real-

Time Simulation.

In: IEEE conference proceedings

N.B. When citing this work, cite the original published paper.

Permanent link to this version:

http://urn.kb.se/resolve?urn=urn:nbn:se:kth:diva-157127 


\title{
Implementation of Conventional and Phasor Based Power System Stabilizing Controls for Real-Time Simulation
}

\author{
M.S. Almas and L. Vanfretti
}

\begin{abstract}
This paper presents the implementation of three different types of Power System Stabilizers (PSS) and a Static Var Compensator with a supplementary Phasor Power O scillation Damper (POD) control for real-time simulation. The Klein-Rogers-Kundur model is used as test case and the PSS and $P h$ asor-POD's performance is evaluated for both large and $\mathrm{sm}$ all disturbances. Modeling is performed in the MATLAB/Simulink environment and is executed in real-time using Opal-RT's eMEGAsim Real-Time Simulator. The simulation results and the developed model will be used to deploy hardware prototype based on embedded controllers to provide power oscillation damping. Real-time software in the loop (SIL) approach is used for validating de veloped models as a first logical step towards development of a prototype hardware controller.
\end{abstract}

Index Terms-Power System Stabilizer, Power Oscillation Damping, Static VAR Compensator, Real-Time Simulation, O pal-RT, SmarTS-Lab

\section{INTRODUCTION}

Historically, the power flows in power systems were very well defined. It was essentially a unidirectional power flow from the major generating sites to the load centres [1]. However this trend is changing now. With more and more integration of renewable energies, the generating capacity of the wind/solar farms could be reduced from $100 \%$ to $10 \%$ within an hour or even minutes due to natural behavior (wind speed, irradiation, etc.). Thus, power flows in the network shift very quickly [2]. As a result, system dynamics change. Small disturbances such as changes in loads or large disturbances like generator outage or a high voltage transmission line fault may result in undamped power oscillations in a heavily loaded interconnected power system [3]. Thes e undamped oscillations if not adequately addressed, result in loss of synchronism of one or group of machines from the rest of the power systemand may cause the system to collapse. This is called rotor angle instability and is mostly dominated by low frequency inter-area oscillations [4].

In order to provide adequate damping to these inter-area oscillations, Power System Stabilizers (PSS) [5] and supplementary control ofFlexible AC Transmission Systems (FACTS) devices are used (referred as Power Oscillation Dampers (POD) [6]). In this paper, Klein-Roger-Kundur power system test case is modelled in MATLAB/Simulink

This work was supported in part by Nordic Energy Research through the STRONg ${ }^{2}$ rid project and by Statnett SF, the Norwegian TSO.

M. S. Almas, and L. Vanfretti are with KTH Royal Institute of Technology, Stockholm, Sweden. (e-mail: \{msalmas, luigiv\}@kth.se)

L. Vanfretti is with Statnett SF, Research and Development, Oslo, Norway (email: \{luigi.vanfretti, stig.lovlund, jan.gjerde\}@statnett.no together with different PSS and Static VAR Compensator (SVC) Phasor-POD implementation. The model is analysed by introducing both large and small disturbances to validate the performance of PSS and POD to damp the inter-area os cillations. Real-time software in the loop (SIL) approach is used where both the controllers (PSS and POD) and the plant (power systemmodel) are executed in the real-time simulator which is the first logical step towards development of a prototype hardware controller [7]. The simulation results and the developed model will be used to deploy power os cillation damping algorithms in embedded controllers to perform decentralized control of power systemoscillations and will be validated using Real-Time Hardware-in-the-Loop (RT-HIL) approach. These results will be submitted in a future publication.

The paper is organized as follows: Section II provides information about the modelling of the test case in MATLAB/Simulink. Section III presents the modelling of three different PSSs namely Multi-Band (MB-PSS), DeltaSpeed (dw-PSS) and Delta-Accelerartion Power (dPa-PSS) and their performance in damping the inter-area oscillations. An average model of a SVC together with Phasor-POD implementation and its performance for os cillation damping is discussed in Section IV. Section V discusses the simulation results and in Section VI, conclusions are drawn and future work is summarized.

\section{Power System Modeling}

In order to investigate the performance of different Power System Stabilizers (PSS) and Power Oscillation Dampers (POD), the Klein-Rogers-Kundur test system was modeled in the MATLAB/Simulink environment using the SimPowerSystems ${ }^{1}$ Library and was executed in real-time using Opal-RT's eMEGAsim Real-Time Simulator ${ }^{2}$. The single line diagram of the test case is shown in Figure 1. The test system consists of two fully symmetrical areas linked

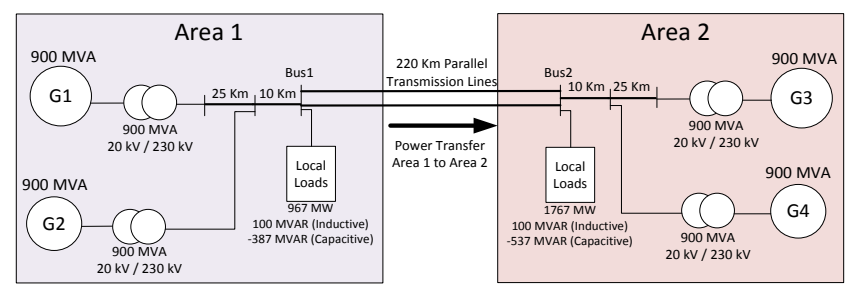

Fig. 1. Single line diagram of test case power system model

The MathWorks, "SimPowerSystems User's Guide," available on-line: http://www.mathworks.com/help.

Opal-RT, "eMEGAsim PowerGrid Real-Time Digital Hardware in the Loop Simulator," available on-line: http://www.opal-rt.com/ 
together by two $230 \mathrm{kV}$ lines of $220 \mathrm{~km}$ length. Each area is equipped with two identical round rotor generators rated 20 $\mathrm{kV} / 900 \mathrm{MVA}$. The nominal power system frequency for the test case model is $50 \mathrm{~Hz}$. It was specifically designed in [8] to study low frequency electromechanical os cillations in large interconnected power systems. The load is represented as constant impedances and split between the areas in such a way that area 1 is exporting power to area 2 .

In order to analyze the response of the power system, a large disturbance in the form of three phase to ground fault (4 cycles i.e. $80 \mathrm{msec}$ ) at $\mathrm{t}=20 \mathrm{sec}$ is introduced in the middle of one of the two $220 \mathrm{~km}$ transmission line connecting Area 1 with Area 2. This results in an un-damped oscillation of 0.64 $\mathrm{Hz}$ which is observable in the tie-line power transfer between Area 1 and Area 2 as shown in Figure 2. In the second scenario 5\% magnitudepulse was applied for 4 cycles at the voltage reference of generator G1 in Area 1. The system response to this perturbation is shown in Figure 3. This is an inter-area mode involving both the machines in Area 1 oscillate against the machines in Area 2. The models of PSS and POD discussed in the next section are designed to damp this inter-area mode of $0.64 \mathrm{~Hz}$.
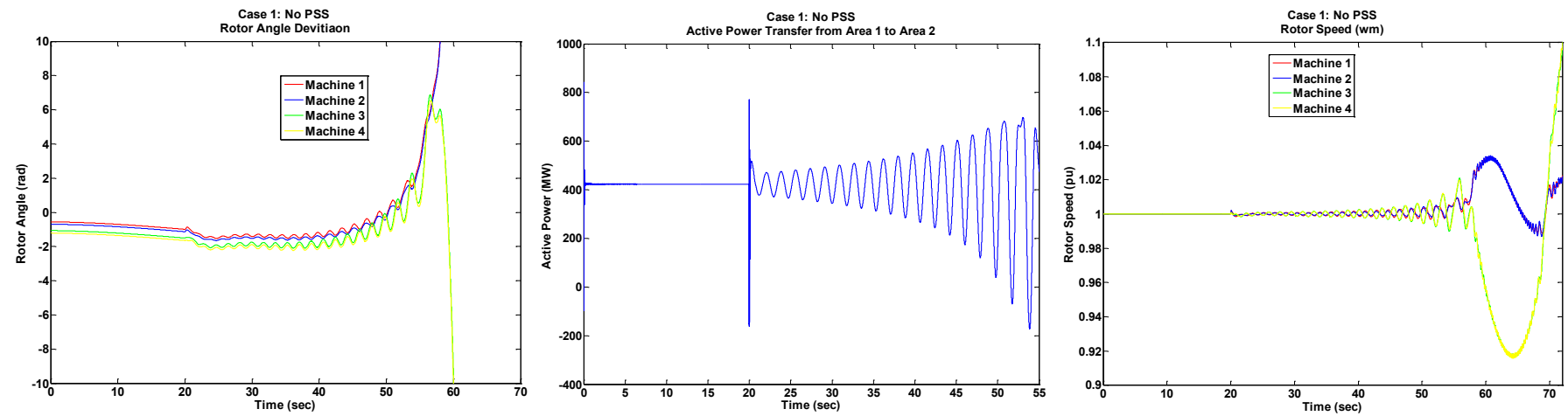

Fig. 2. Response of Test Case model when three phase to ground fault ( 4 cycles) is introduced at the middle of one of the $220 \mathrm{kV}$ tran smission lines at $\mathrm{t}=20 \mathrm{sec}$ Rotor angle deviation (left), power transfer from Area 1 to Area 2 (middle) and rotor speed of all the generators (right) are shown.
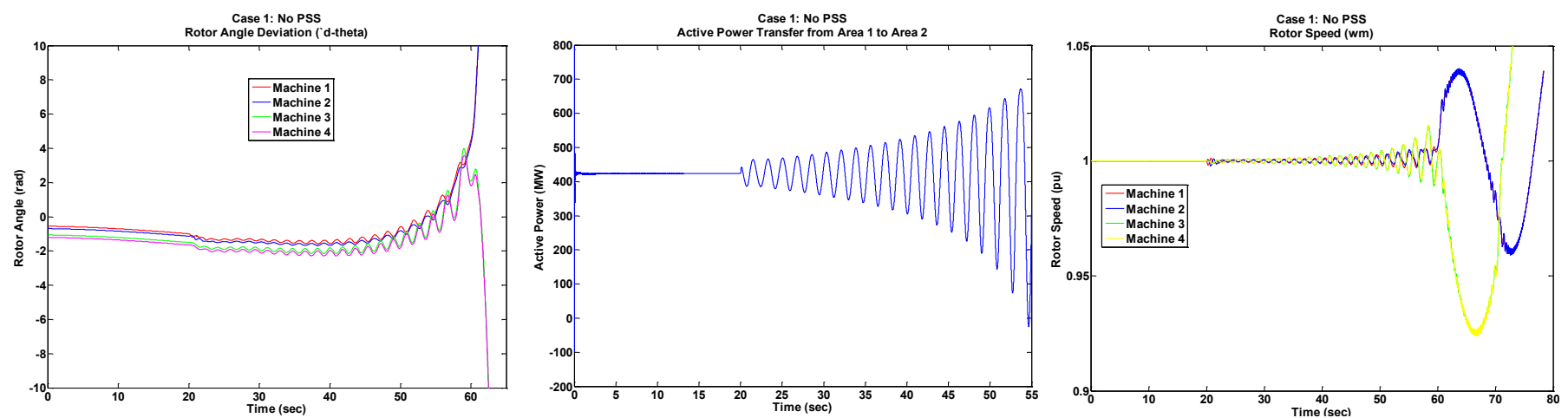

Fig. 3. Response of Test Case model when a $5 \%$ magnitude step is applied at the reference voltage of Generator 1 at $\mathrm{t}=20$ sec. Rotor angle deviation (left), power transfer from Area 1 to Area 2 (middle) and rotor speed of all the generators (right) are shown. An inter-area oscillation of $0.64 \mathrm{~Hz}$ is observable in the tie-line power (middle).

\section{Power System Stabilizer (PSS) Modeling}

In order to provide appropriate damping for this $0.64 \mathrm{~Hz}$ inter-area mode, three different PSS designs were modeled and implemented in MATLAB/Simulink. The PSS output is provided as an additional input to the excitation system of synchronous generator used to add damping to the rotor oscillations of the synchronous machine by controlling its excitation. The different PSS implemented for damping the $0.64 \mathrm{~Hz}$ mode are discussed individually below;

\section{A. Multi-Band PSS}

The IEEE type PSS4B PSS is described in the IEEE Standard 421.5 [9] and is available in the SimPowerSystems library. This block was tuned to provide damping for the inter-area oscillation mode of $0.64 \mathrm{~Hz}$. The model is shown in Figure 4 and is presented in [10]. It consists of three bands namely low, intermediate and high band. The low band takes care of very slow oscillating phenomena (i.e. drift mode). The intermediate band is used for inter-area modes usually found in the range of 0.2 to $1.0 \mathrm{~Hz}$. The high band deals with local

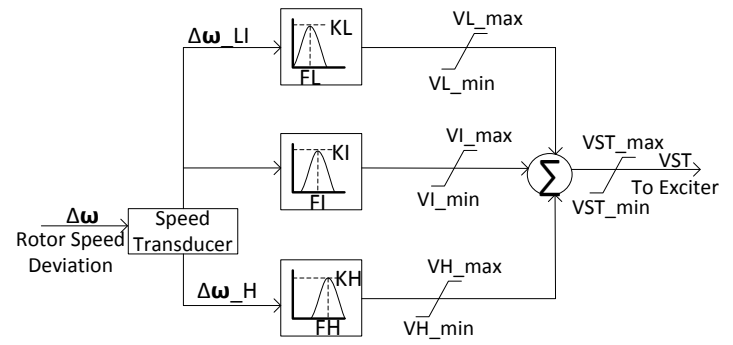

Fig. 4. MB-PSS simplified model with $\mathrm{K}_{\mathrm{L}}=30, \mathrm{~F}_{\mathrm{L}}=0.05 \mathrm{~Hz} ; \mathrm{K}_{\mathrm{i}}=40.0 \mathrm{~F}_{\mathrm{I}}=$ $0.80 \mathrm{~Hz} ; \mathrm{K}_{\mathrm{H}}=160.0 \mathrm{~F}_{\mathrm{H}}=8.0 \mathrm{~Hz}$ 
modes either plant or inter-machines, with a typical frequency range of 0.8 to $4.0 \mathrm{~Hz}$. In this study, only the inter-area mode of oscillation is of interest therefore, the local modes of the test case power system are neglected. As shown in Figure 4, the input to the MB-PSS is the rotor speed deviation and output is a stabilizing signal which is added to the excitation system of synchronous generator to provide adequate damping. The response of the test case model in presence of MB-PSS for both large and small disturbances is shown in Figure 5 and Figure 6 respectively.
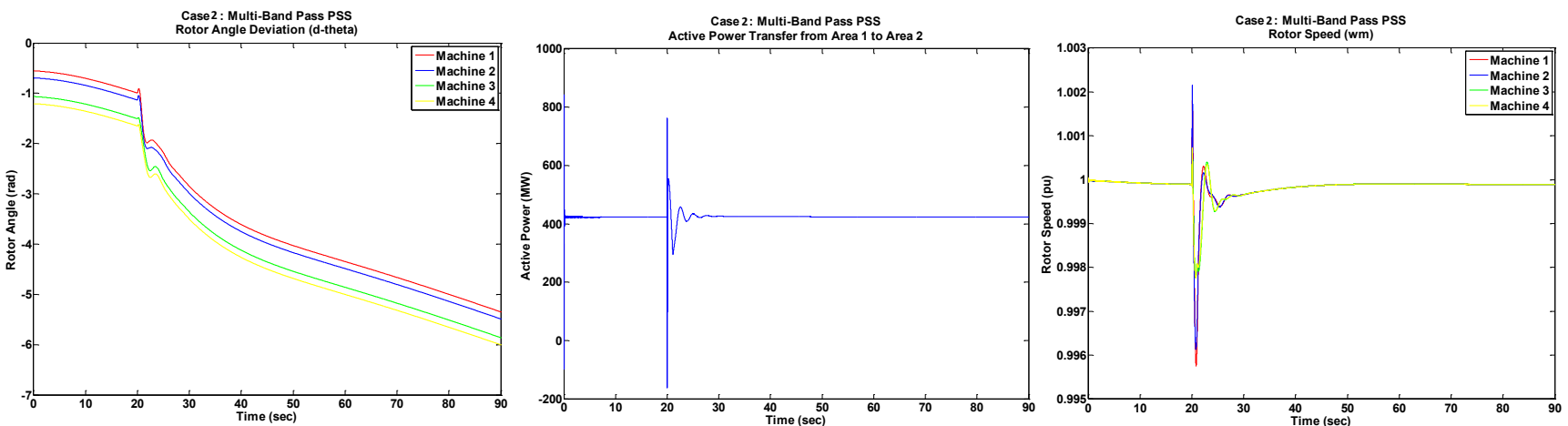

Fig. 5. Response of Test Case model when three phase to ground fault ( 4 cycles) is introduced at the middle of one of the $220 \mathrm{kV}$ tran smission lines at $\mathrm{t}=20 \mathrm{sec}$ in presence of MB-PSS. Rotor angle deviation (left), power transfer from Area 1 to Area 2 (middle) and rotor speed of all the generators (right) are shown. The inter-area oscillation of $0.64 \mathrm{~Hz}$ is adequately damped.
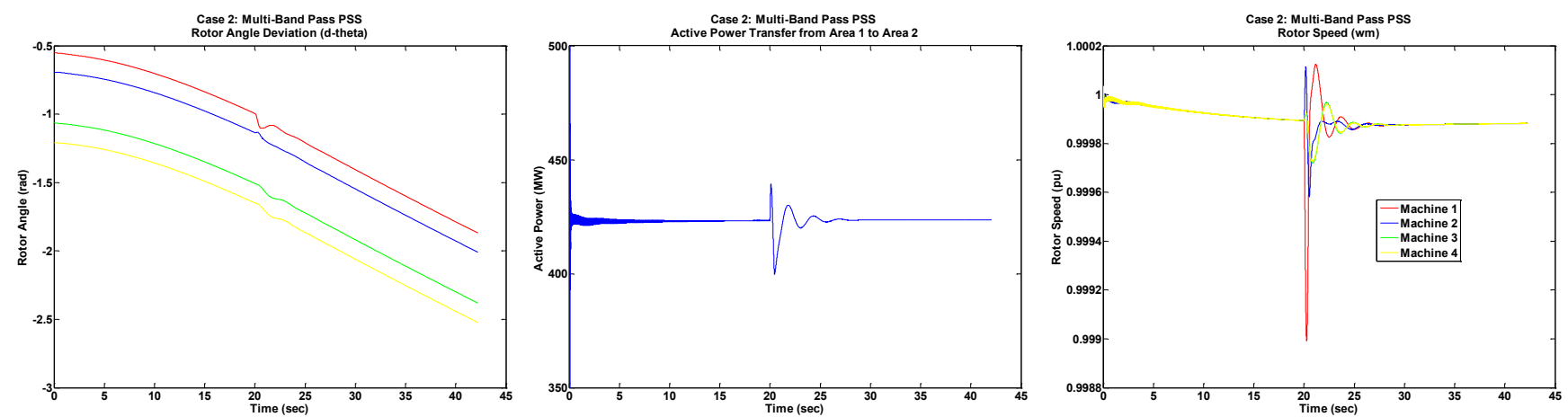

Fig. 6. Response of Test Case model when a $5 \%$ magnitude step is applied at the reference voltage of Generator 1 at $\mathrm{t}=20$ sec in presence of MB-PSS. Rotor angle deviation (left), power transfer from Area 1 to Area 2 (middle) and rotor speed of all the generators (right) are shown. The inter-area oscillation of 0.64 $\mathrm{Hz}$ is adequately damped.

\section{B. ConventionalDelta $\boldsymbol{\omega} P S S$}

The simplest method to provide a damping torque in the synchronous machine is to measure therotor speed and use it directly as an input signal in the stabilizer structure. This PSS modelwas first proposed in [11] and is illustrated in Figure 7. It consists of a low-pass filter, a gain, a washout filter which is effectively a high-pass filter, a phase-compensation system in the form oflead-lag compensator, and an output limiter. The general gain " $\mathrm{K}$ " determines the amount of damping produced by the stabilizer. The washouthigh-pass filter allows the PSS to respond only to transient variations in speed input signal " $\mathrm{d} \boldsymbol{\omega}$ ". The phase-compensation systemis repres ented by leadlag transfer functions used to compensate the phase lag between the excitation voltage and the electrical to rque of the synchronous machine to provide adequate damping. The output limiter ensures to bound the controls action of a PSS during a major system dis turbance and thus avoids the PSS to adversely affect the generator's synchronism. All the parameters of the delta $\boldsymbol{\omega}$ PSS are set according to [12]. The response of the test case powersystem in presence of delta $\boldsymbol{\omega}$
PSS for both large and small disturbance is shown in Figure 9 and Figure 10 respectively.

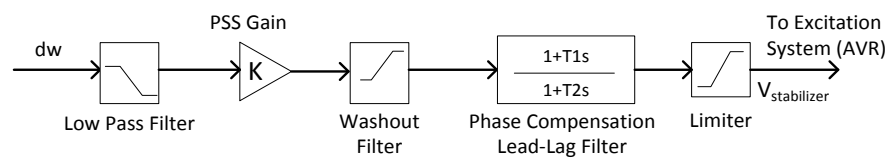

Fig. 7. Model of conventional $\Delta \boldsymbol{\omega}$ PSS [11]. PSS Gain (K) is set to 20, T1 and $\mathrm{T} 2$ for phase compensation are set to 0.05 and 0.02 respectively.

\section{Conventional Acceleration Power (Delta Pa) PSS}

Acceleration power of a generator is defined as the difference between its mechanical input power and electrical power output. This acceleration power is used as an input signal for conventional PSS model presented in Figure 7.

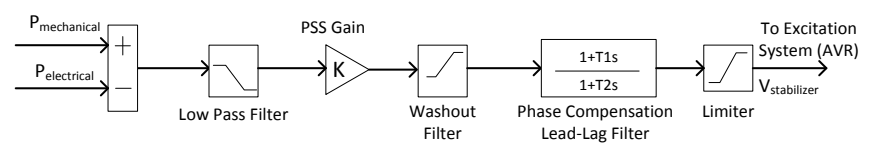

Fig. 8. Model of conventional $\triangle \mathrm{Pa}$ PSS. PSS Gain (K) is set to 3.5, T1 and $\mathrm{T} 2$ for phase compensation are set to 0.06 and 1 respectively. 
The model of Delta Pa PSS is shown in Figure 8. The

PSS for both large and small disturbance is shown in Figure response of the test case power systemin presence of delta $\mathrm{Pa} \quad 11$ and Figure 12 respectively.
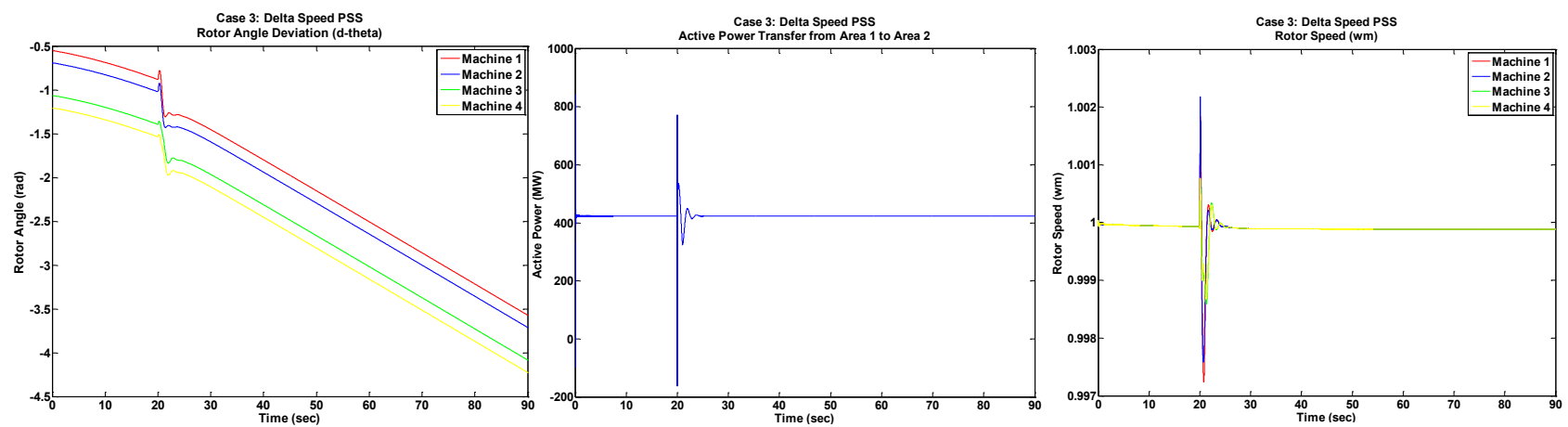

Fig. 9. Response of Test Case model when three phase to ground fault ( 4 cycles) is introduced at the middle of one of the $220 \mathrm{kV}$ tran smission lines at $\mathrm{t}=20 \mathrm{sec}$ in presence of dw-PSS. Rotor angle deviation (left), power transfer from Area 1 to Area 2 (middle) and rotor speed of all the generators (right) are shown.
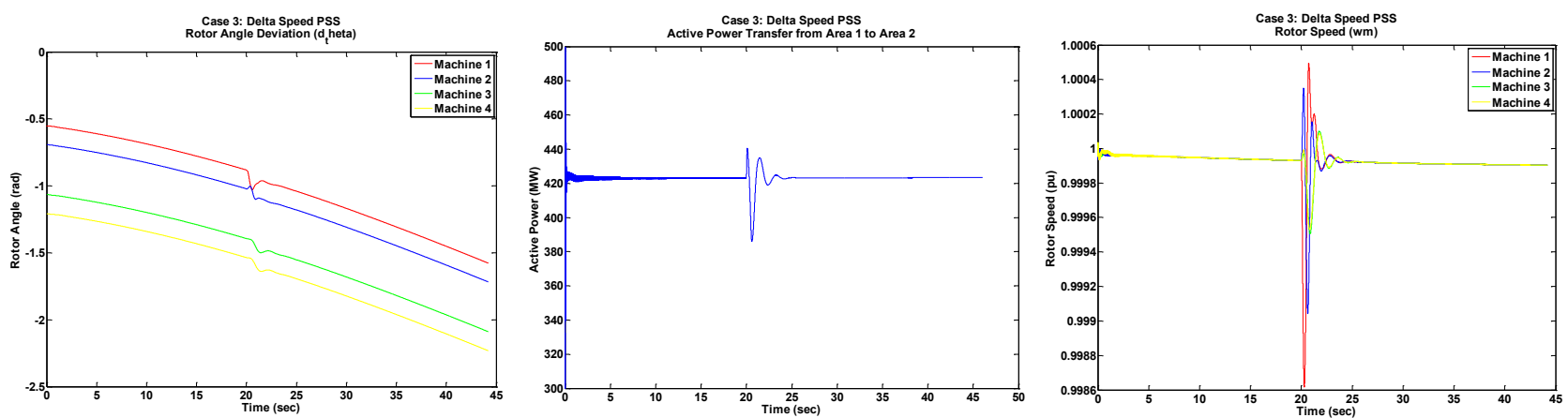

Fig. 10. Response of Test Case model when a $5 \%$ magnitude step is applied at the reference voltage of Generator 1 at $\mathrm{t}=20$ sec in presence of $\mathrm{d} \boldsymbol{\omega}$-PSS. Rotor angle deviation (left), power transfer from Area 1 to Area 2 (middle) and rotor speed of all the generators (right) are shown. The inter-area oscillation of 0.64 $\mathrm{Hz}$ is adequately damped.
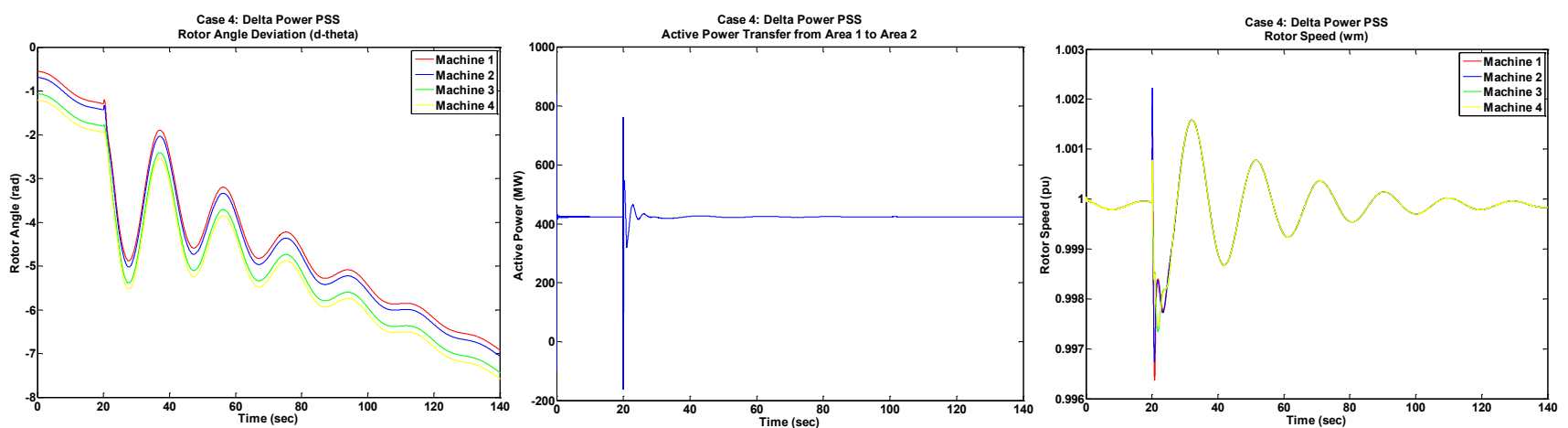

Fig. 11. Response of Test Case model when three phase to ground fault ( 4 cycles) is introduced at the middle of one of the $220 \mathrm{kV}$ tran smission lines at $\mathrm{t}=20$ sec in presence of $\triangle$ Pa-PSS. Rotor angle deviation (left), power transfer from Area 1 to Area 2 (middle) and rotor speed of all the generators (right) are shown.
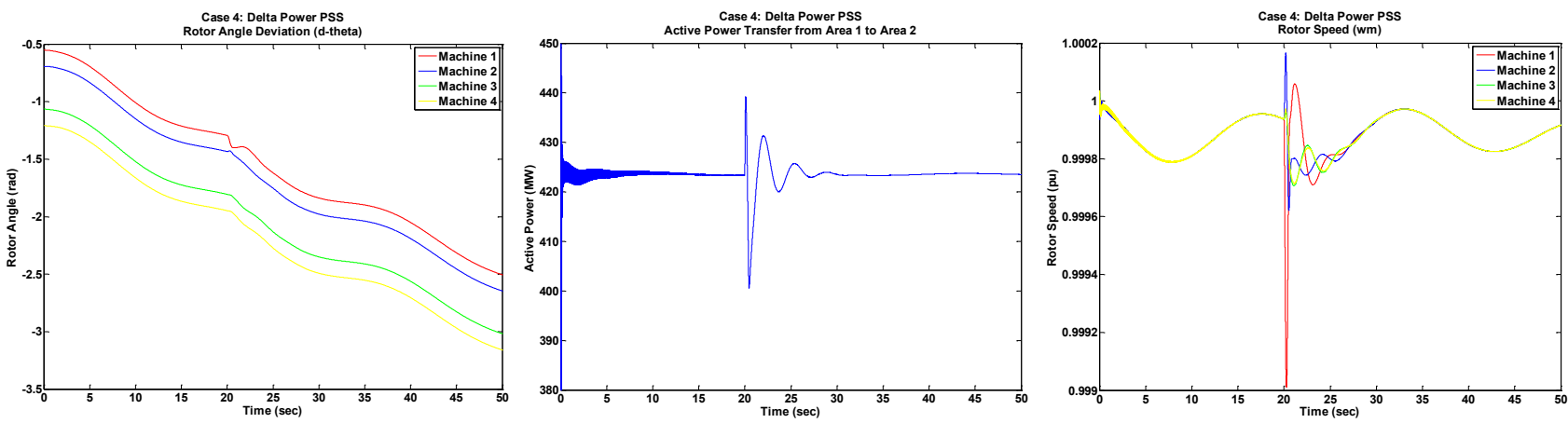

Fig. 12. Response of Test Case model when a $5 \%$ magnitude step is applied at the reference voltage of Generator 1 at $\mathrm{t}=20$ sec in presence of $\Delta \mathrm{Pa}$-PSS. Rotor angle deviation (left), power transfer from Area 1 to Area 2 (middle) and rotor speed of all the generators (right) are shown. . 


\section{St ATIC VAR COMPENSATOR (SVC) AND POWER OSCILLATION DAMPER (POD)}

Power os cillation damping can be effectively achieved by supplementary control ofFlexible AC Transmis sion Systems (FACTS) devices [13]. For this study, an average model of a Static Var Compensator (SVC) is implemented in MATLAB/Simulink to provideadequate damping to the 0.64 $\mathrm{Hz}$ os cillatory mode in addition to providing reactive power support at the mid-point of the $220 \mathrm{~km}$ long transmission line connecting Area 1 with Area 2 (see Figure 1).

\section{A. SVC ModelDeveloped in MATLAB/Simulink}

In this study an average model of SVC is developed in MATLAB/Simulink which exhibits the behavior required for small signal stability analysis. The model developed is shown in Figure 13. The voltage error signal at the mid-point is fed to a PID controller which provides a value of the susceptance $\left(\mathrm{B}_{\mathrm{SVC}}\right)$ of the SVC. This susceptance is used to compute three phase current which is injected at the SVC's point of connection to increase or decrease the voltage at the bus. In order to verify the performance of the developed model for voltage control at midpoint, $\mathrm{V}_{\text {reference }}$ of SVC is changed to 1 pu at $\mathrm{t}=40 \mathrm{sec}$, then to $0.97 \mathrm{pu}$ at $\mathrm{t}=60 \mathrm{sec}$ and finally back to 1 pu at $\mathrm{t}=90 \mathrm{sec}$. Figure 14 shows the response of midpoint voltage of the test case power system for these changes in $\mathrm{V}_{\text {reference }}$ of SVC. Figure 15 shows different SVC parameters and the effect of changes in the reference voltage to the power transfer between Area 1 and Area 2.
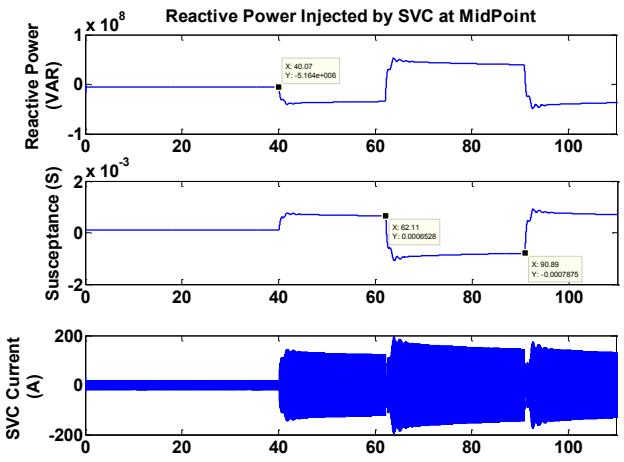

Fig. 15. Reactive power injected by SVC, susceptance and current injected at the midpoint (Left), power transfer between Area 1 and Area 2 (Right).

\section{B. Power Oscillation Damper Implementation}

Conventional PODs or PSS based on lead-lag compensation systems require a detailed model of the system at specific operating condition. These controllers provide appropriate phase shift and thus oscillation damping within a certain operating condition [8]. It is cumbers ome to accurately model each and every dynamic component to compute the necessary gain and phase shift required for providing appropriate damping. In addition, the complexity of the large inter-connected power systems may lead to varying operating conditions which might not be considered when computing parameters of conventional PSS or PODs [14].

Another approach for generating command signals for damping is called phasor POD proposed in [15]. The principle

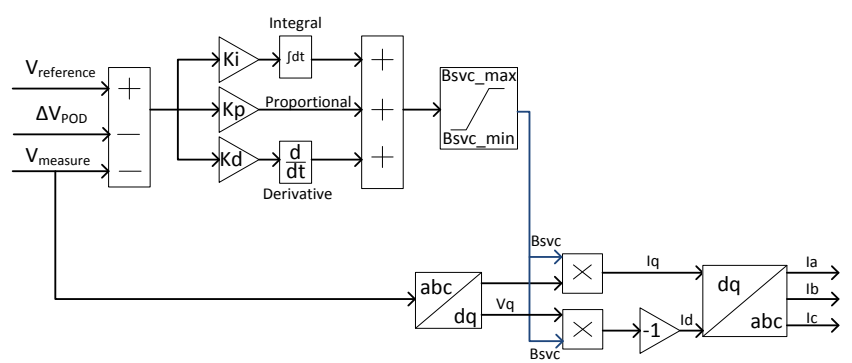

Fig. 13. Average model of SVC developed in MATLAB/Simulink and coupled at the midpoint of the $220 \mathrm{~km}$ long transmission line of the test case system.

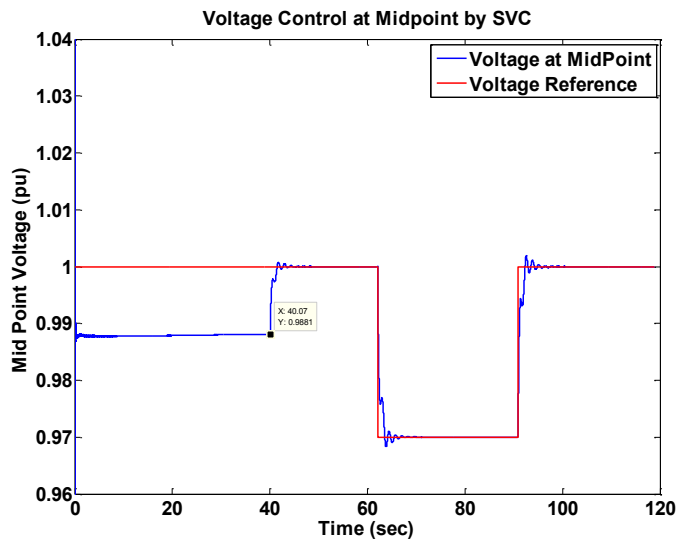

Fig. 14. Midpoint voltage of the test case system. The voltage reference of the SVC model is changed to control the midpoint voltage.

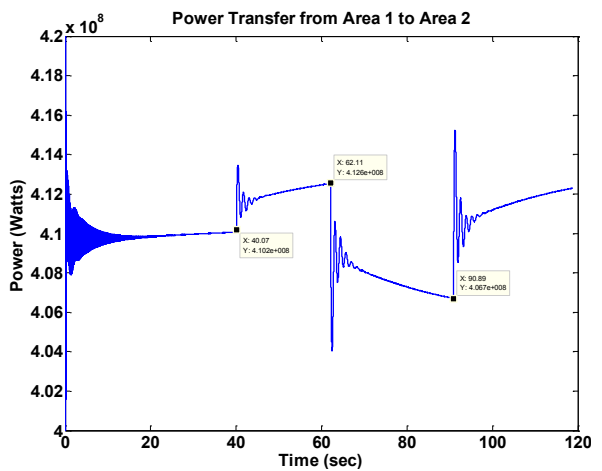

for creating the damping signal using the Phasor POD approach is shown in Figure 16.

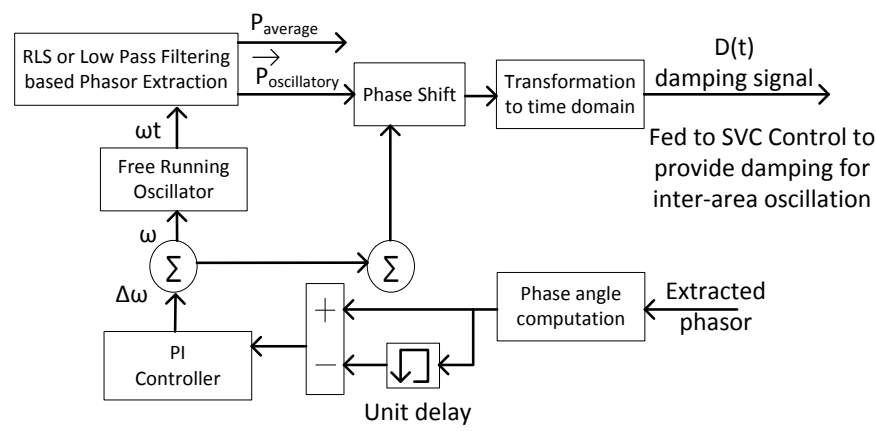

Fig. 16. Operating principle of Phasor POD and generation of control signal for SVC to provide power oscillation damping 
The main objective is to separate the os cillatory part of the input signal from the average value. The os cillatory part of the measured input signal is extracted as a phasor by using either recursive least square estimation technique or a low pass filter. The damping signal is computed by applying appropriate phase shift on the extracted oscillatory signal phasor [15].
This damping signal is provided as one of the inputs to the developed SVC model (see Figure 13) which results in voltage error in case of oscillatory content in the measured input signal to the POD. The response of the test case power system in presence of Phasor POD for both large and small disturbance is shown in Figure 17 and Figure 18 respectively.
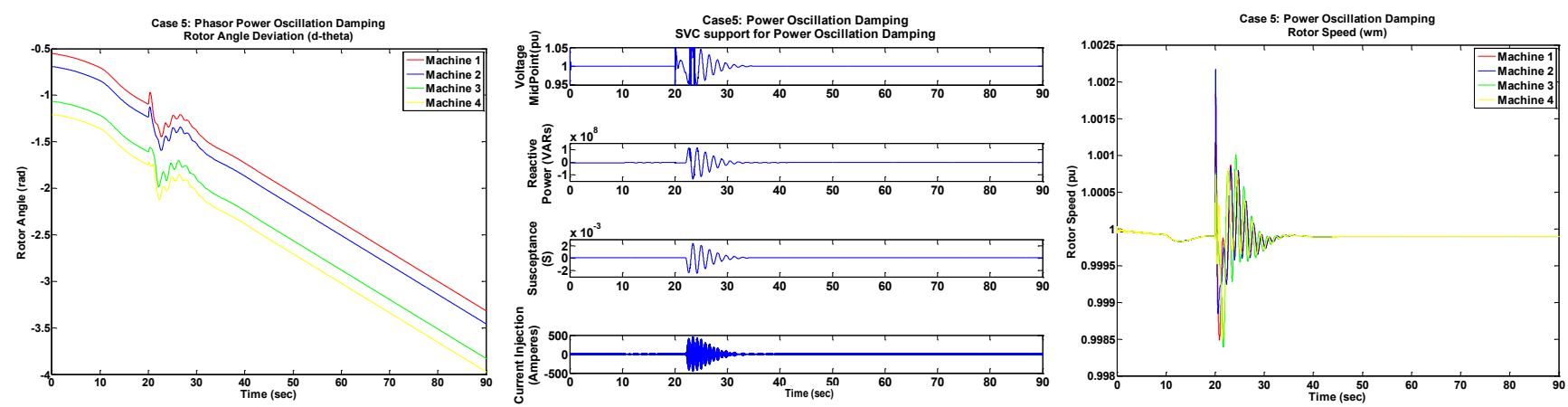

Fig. 17. Response of Test Case model when three phase to ground fault (4 cycles) is introduced at the middle of one of the $220 \mathrm{kV}$ tran smission lines at $\mathrm{t}=20$ sec in presence of phasor POD and SVC. Rotor angle deviation (left), SVC reactive power (middle) and rotor speed of all the generators (right) are shown.
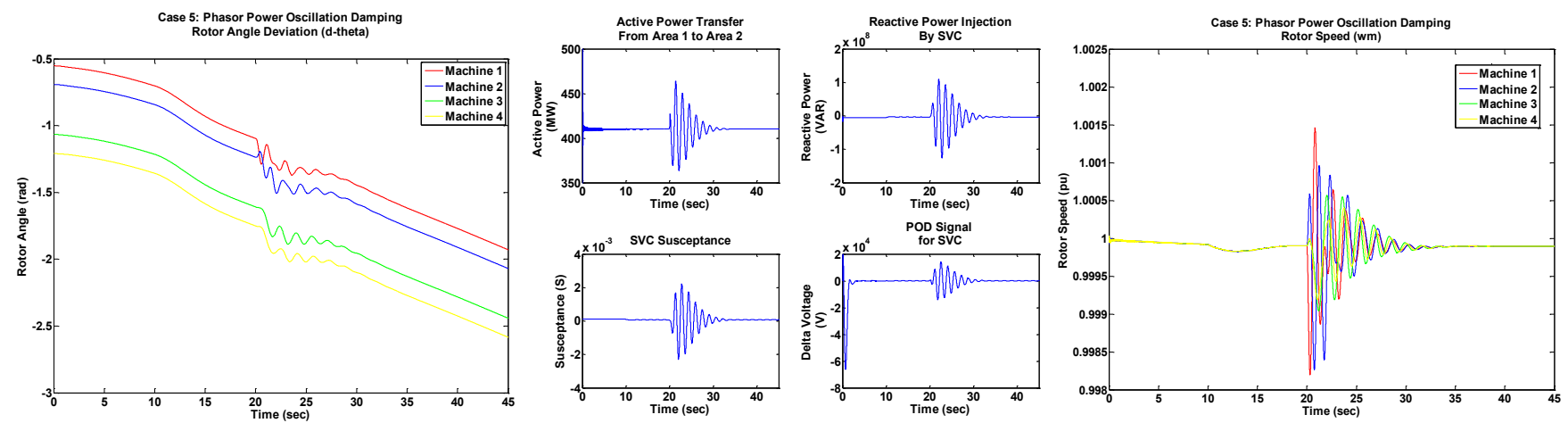

Fig. 18. Response of Test Case model when a $5 \%$ magnitude step is applied at the reference voltage of Generator 1 at $\mathrm{t}=20 \mathrm{sec}$ in presence of Phasor POD and SVC. Rotor angle deviation (left), power transfer from Area 1 to Area 2 together with SVC susceptance and reactive power injections (middle) and rotor speed of all the generators (right) are shown. The inter-area oscillation of $0.64 \mathrm{~Hz}$ is adequately damped.

\section{Discussion on Simulation Results}

Rotor angle deviation of Generator 1 and power transfer between Area 1 and Area 2 is presented for large disturbance (three phase fault) for all the cases in Figure 19. In absence of a PSS or POD, the system is unstable (grey trace) and the 0.64 $\mathrm{Hz}$ oscillatory mode is visible in the active power transfer between Area 1 and Area 2 when subjected to either small or large disturbance. All the PSS types provide adequate damping for $0.64 \mathrm{~Hz}$ mode. The MB-PSS (blue trace) has a large overshoot instantly after the fault is applied but provides fastest damping as compared to the other two PSS. The overshoot can be reduced by optimizing the limiters (VL max and VL min) in Figure 4. MB-PSS has the capability of damping both inter-area and local modes and its capabilities with respect to other two PSS can be better unders tood if the system contains atleast one dominant local mode (which is neglected in this study). Delta- $\omega$ PSS (green trace) has a better response as compared to delta-Pa PSS (yellow) because of
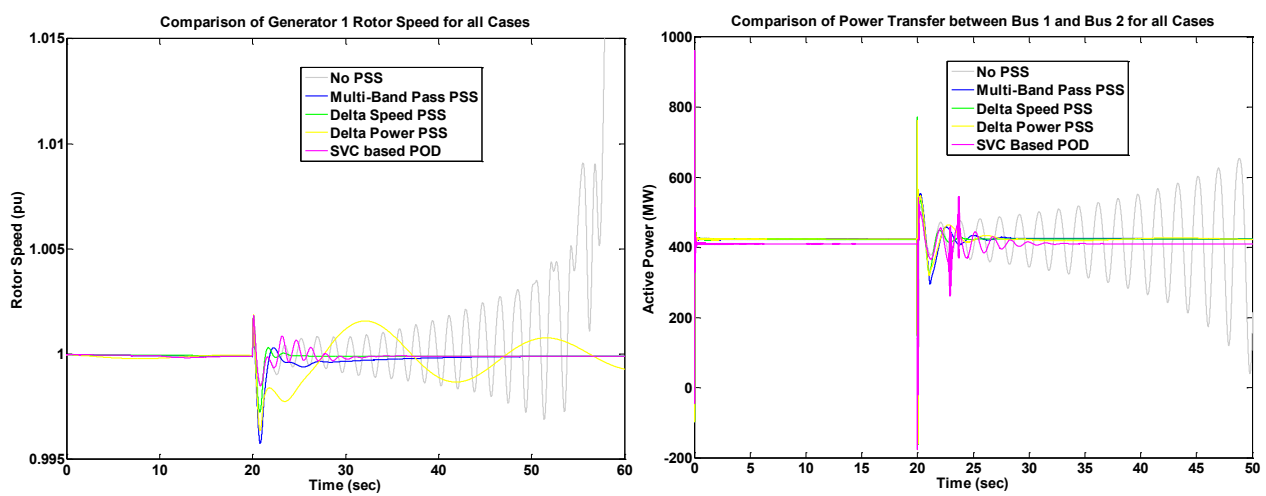

Fig. 19. Response of Generator 1 rotor speed when three phase to ground fault ( 4 cycles) is introduced at the middle of one of the $220 \mathrm{kV}$ transmission lines at $\mathrm{t}=20 \mathrm{sec}$ for all the cases (left). Power transfer between Area 1 and Area 2 for all the test cases (right) are shown.. 
the dependence of delta-Pa PSS on mechanical power input $\left(\mathrm{P}_{\mathrm{a}}=\mathrm{P}_{\text {mech }}-\mathrm{P}_{\text {elect }}\right)$ of the generator which is regulated by turbine governor control. This results in delta-Pa PSS to respond to slow dynamics of the interaction between synchronous machine inertia and turbine's governor control for regulating speed of the machine in an aftermath of disturbance and as a result it takes a longer time to damp the oscillations as compared to delta- $\omega$ PSS.

The performance of phasor POD (magenta trace) shows a relatively slower response in damping out the $0.64 \mathrm{~Hz}$ mode as compared to MB-PSS or Delta- $\omega$ PSS. This is because the recursive technique is used to estimate phasor of the oscillatory part in the input measured signal. Recursive least square method yields somewhat less accurate phasor estimation during the first cycle. In addition the gain for the phasor POD is kept relatively low, so that the SVC does not adversely affect the system synchronism by injecting or absorbing significant reactive power.

In order to implement the average SVC model for real-time execution, an Artemis Stub-Line block [16] was used which provides exactly one time step propagation delay to avoid algebraic loops in the model. This stub-line injects some reactive power into the network. In order to cancel out the additional reactive power, a fixed inductor was used in series to the stub-line. In addition the stub-line resistance causes some active power dissipation across it which is visible in Figure 19 (Right). This results in relatively less power transfer from Area 1 to Area 2.

All the test scenarios are executed in real-time using four cores of Opal-RT's eMEGAsim Real-Time simulator with a discrete step size of $50 \mu \mathrm{sec}$. The real-time computation time is less than $10 \mu \mathrm{sec}$ which is well below $50 \mu$ sec step size and thus no over-runs were detected for all the test cases.

\section{CONCLUSION AND FUTURE WORK}

The performance of three different types of power system stabilizers together with an SVC with supplementary PhasorPOD control were implemented to provide damping enhancement in the Klein-Rogers-Kundur test power system model. An average model of an SVC together with a PhasorPOD implementation was also presented. Multi-Band PSS shows the fastest response for os cillation damping. The Static VAR Compensator model when coupled with the test case system together with Phasor-POD implementation provided both reactive power support and adequate damping for 0.64 $\mathrm{Hz}$ mode. Real-time software in the loop (SIL) approach is used where both the controllers (PSS and POD) and the plant (power systemmodel) are executed in the real-time simulator which is the first logical step towards development of a prototype hardware controller.

The models developed in this study together with the Phasor-POD algorithm will be implemented in the National Instruments Compact Reconfigurable I/O (cRIOs) [17] systems for real-time hardware-in-the-loop (RT-HIL) simulation. SmarTS-Lab at KTH has recently commissioned ABB Excitation System Unitrol $1020^{3}$ which will be used for

\footnotetext{
${ }^{3}$ ABB-Unitrol 1020 Automatic Voltage Regulator, available online: http://tinyurl.com/Unitrol
}

RT-HIL simulation to replace the software model for one of the generator's excitation control system in the test case system. In addition the System-in-the-Loop (SITL) package [18] together with OPNET network simulator ${ }^{4}$ is being configured in SmarTS-Lab to simulate network delays and latencies in the feedback signal for the PODs to effectively address the effect of communication delays. These results will be submitted in a future publication.

\section{REFERENCES}

[1] G. Heydt, C. Liu , A. Phadke and V. Vittal "Solution for the crisis in electric power supply", IEEE Comput. Appl. Power, vol. 14, no. 3, pp.22 -302001

[2] D. Gautam, V. Vittal and T. Harbour, "Impact of Increased Penetration of DFIG-Based Wind Turbine Generators on Transient and Small Signal Stability of Power Systems" IEEE Transactions on Power Systems, Vol. 24, No. 3, August 2009, pp. 1426 - 1434

[3] G. Rogers, "Power System Oscillations", Kluwer Academic Publishers Group, 2000

[4] J.J. Sanchez-Gasca and J.H. Chow, "Performance comparison of three identification methods for the analysis of electromechanical oscillations", IEEE Transactions on Power Systems, Vol. 14, No. 3, August 1999, pp. 995-1002

[5] P. Kundur ; M. Klein G. J. Rogers and M. S. Zywno, "Application of Power System Stabilizers forEnhancement of Overall S ystem Stability”, IEEE Transactions on Power Systems, Vol. 4, No. 2, August 1989, pp. 614-626

[6] L. Angquist, B. Lundin and J. Samuelsson, "Power oscillation damping using controlled reactive power compensation-a comparison between series and shunt approaches", IEEE Transactions on Power Systems, Vol. 8 , No. 2, July 1993 , pp. $687-700$

[7] J. Belanger, P. Venne, and J. N. Paquin, "The What, Where and Why of Real-Time Simulation", Technical report, Opal-RT Technologies. Available at: http://www.opal-rt.com/technical-document/what-whereand-why-real-time-simulation.

[8] M. Klein , G. Rogers and P. Kundur "A fundamental study of interarea oscillations in power systems", IEEE Trans. Power Syst., vol. 6, no. 3, pp.914 -921 1991

[9] IEEE Std 421.5-2005, "IEEE Recommended Practice for Excitation System Models for Power System Stability Studies", 2005

[10] R: Grondin, I. Kamwa, et.al, “ Modeling and closed-loop validation of a new PSS concept, the multi-band PSS", IEEE Power Engineering Society General Meeting, 13-17 July, 2003, Toronto, Canada

[11] M. Klein, J. Rogers, S. Moorty and P. Kundur: "Analytical investigation of factors influencing PSS performance," IEEE Transactions on Energy Conversion, Vol. 7 , No 3, September 1992, pp. $382-390$

[12] P. Kundur, M. Klein, G. J. Rogers and M.S. Zywno, "Application of Power System Stabilizers for Enhancement of Overall System Stability”, IEEE Transactions on Power System, Vol. 4, Issue 2, pp. 614-626, May 1989

[13] N. Mithulananthan, "Comparison of PSS, SVC, and STATCOM controllers for damping power system oscillations", IEEE Transactions on Power Systems, Vol. 18, Issue 2, pp. 786-792, May 2003

[14] N. R. Chaudhuri , S. Ray, R. Majumder and B. Chaudhuri "A case study on challenges for robust wide-area phasor POD", Proc. IEEE Power Eng. Soc. General Meeting, 2009

[15] L. Angquist and C. Gama, " Damping algorithm based on phasor estimation”, IEEE Power Engineering Society Winter Meeting, 2001, Vol. 3, pp. 1160-1165

[16] ARTEMiS Stubline - decoupling of state-space system equations of networks on both sides of the stubline and eliminates algebraic loop. http://www.opalrt.com/sites/default/files/ARTEMIS_User_Guide(1).pdf

[17] National Instrument- Compact Reconfigurable I/O Systems (NIcRIOs), available online: www.ni.com/compactrio/

[18] K. McNeill, R. Martinez, W. Wu, and J. Deal, "HITL /SITL General Reference Model," OPNETworks 2003 Symposium, Washington DC,August 2003

${ }^{4}$ OPNET Modeler for communication Network Simulation, OPNET Technologies. http://www.OPNET.com 